\title{
Метакорпорации: природа их образования и роль в современной мировой экономике
}

\author{
Голикова Ю.А. ${ }^{13}$
}

В статье раскрыто понятие метакорпорации, проанализирована природа ее образования и развития; представлень основные структурные формы и типь метакорпоращий; уточнено определение, дана характеристика и обозначень основные векторы развития мировой системы метакорпораций.

\section{JEL: L20, M16, F23.}

Ключевые слова: метакорпоращия, организационная структура метакорпоращий, типы метакорпораций, мировая система метакорпораций

Эволюционное развитие корпораций, их взаимодействие и конкуренция в рамках глобальной рыночной экономики объективно привели к возникновению принципиально нового вида компаний, точнее их объединения. Процессы объединения разрозненных, самостоятельно функционирующих корпораций лежат в основе формирования целостных образований, где все элементы являются частями единого экономического организма. Соединяя потенциалы различных предприятий, дополняющих друг друга, объединенные корпоративные образования стремятся к получению синергетического эффекта и роста эффективности. Особенный интерес в современных условиях вызывают интегрированные корпоративные образования (объединения корпораций), характеризующиеся собственными закономерностями развития, но не имеющие общепринятого однозначного определения для их обозначения. Для современной экономической литературы типично обилие терминологических новинок, при которых термин «корпорация» фигурирует в различных сочетаниях с такими определениями, как «многонациональная», «транснациональная», «межнациональная», «сверхнациональная», «глобальная». Используются понятия: «макроструктура» (Беляева, 1998]), «сверхкорпорация» (Annual report... 1992-1999]), «интегрированная корпоративная структура» (Винслав, 2000]), «связаннодиверсифицированная система» (Забелин, 1998]), «интергломерат» (Лафта, 1999]), «интегрированная бизнес-группа» (Авдашева, 1998]), а также «метакорпорация» (Бутчиков, 1997]). Из перечисленных понятие метакорпорации представляется максимально многогранным и универсальным.

Метакорпорации (от греч. meta - между, через, промежуточность, следование за чемлибо, к чему-либо другому) - современные корпоративные образования, объединения нескольких экономических агентов (интегрированные корпоративные образования, комплексные формы промежуточного, переходного статуса), играющие роль центров экономической власти в стране, представляющие национальную экономику на международной арене и удовлетворяющие следующим требованиям:

- часть экономических агентов является коммерческими организациями;

- между агентами существуют устойчивые взаимосвязи (часто объединение выступает как единое целое, но не наделяется статусом юридического лица);

- существует единый стратегический центр принятия решений - центральный элемент корпорации (в форме юридического лица или группы физических лиц - топменеджеров).

Из определения следует, что в структуре любой метакорпорации все юридические лица

\footnotetext{
${ }^{13}$ Канд. эконом. наук, докторант кафедры управления и планирования социально-экономических процессов им. 3.д.н. РФ Ю.А. Лаврикова, Санкт-Петербургский государственный университет экономики и финансов.
} 
подразделяются на материнскую (головную) компанию и сеть многочисленных зависимых дочерних компаний, подконтрольных материнской.

В современных условиях в роли метакорпораций выступают многочисленные монополистические и олигополистические объединения, инвестиционные, финансовые, кредитные и производственные корпоративные образования, несущие социальную ответственность перед страной и обществом.

На практике объединение отдельных компаний в единую действующую структуру (метакорпорацию) сопряжено с многочисленными сложностями. В силу наличия ряда негативных последствий объединения иногда после формальной внешней интеграции некоторые корпоративные образования продолжают функционировать как совокупность отдельных подразделений, имеющих разную производственную инфраструктуру, научноисследовательские и маркетинговые службы. Однако чаще всего большая часть негативных последствий минимизируется либо полностью нейтрализуется за счет синергетического эффекта корпоративной интеграции. Некоторые отрицательные последствия могут быть преодолены посредством избирательного вмешательства (невмешательства) в деятельность соответствующих подразделений.

С точки зрения взаимодействия с внешней средой деятельность метакорпораций осуществляется в рамках двух основных групп функций (Шамхалов, 2000]):

1. Общие функции, выполняемые компаниями в составе метакорпорации (производство товаров и оказание услуг).

2. Специфические функции крупного бизнеса:

2.1. Явные (функция оптимального комбинирования факторов производства, функция образования общественного продукта и содействия распределению национального дохода, функция организации, инновационная функция, функция эффективного удовлетворения спроса и т.п.).

2.2. Скрытые (функция внешнеэкономического представительства национальной экономики, функция осуществления объективной реальной хозяйственной власти в стране и т.п.).

Несмотря на повышенное внимание, уделяемое проблемам функционирования метакорпораций, единой классификации подобного рода корпоративных образований еще не сложилось. Наиболее популярной является классификация с точки зрения их экономикоправовой либо чисто экономической природы, однако данный подход неидеален в силу существования огромного числа исключений. Существует целый ряд корпоративных образований, которые не представляют собой метакорпорации с точки зрения экономикоправового определения, но относятся к таковым с точки зрения экономического определения (горизонтальные, круговые корпорации, компании с дивизиональной структурой). С другой стороны, холдинги, наоборот, формально состоящие из ряда юридических лиц, являются ярким примером метакорпораций с экономико-правовой точки зрения; однако на практике нередко не соответствуют экономическому понятию метакорпораций, являются иерархиями в силу жесткой централизации власти и минимальной самостоятельности отдельных корпораций в составе холдинга. За рубежом различные формы метакорпораций часто не наделены статусом юридических лиц (концерны в ФРГ, Португалии и других странах Европы, холдинговые группы в США и Великобритании, Канаде, Австралии, кейрэцу в Японии, чеболи в Южной Корее, хозяйственные группы в Беларуси, финансовопромышленные группы (ФПГ) в Украине и прочих странах СНГ и др.). С другой стороны, например, в законодательстве Украины ассоциации, концерны, корпорации и консорциумы рассматриваются как юридические лица (Хвалей, 2000]). Многие авторы склонны классифицировать метакорпорации по географическому признаку (признаку принадлежности капитала), выделяя региональные, межрегиональные, федеральные и межгосударственные. Представляет интерес подход Е.Л. Драчевой и А.М. Либман, который заключается в делении метакорпораций на холдинговые - основанные на акционерном способе контроля и отношениях собственности, и нехолдинговые - взаимоотношения внутри 
них регулируются специальными соглашениями.

Известны и другие варианты классификаций, но, несмотря на разнообразие подходов, в целом все исследователи согласны, что в любом из указанных случаев метакорпорации представляют собой объективный продукт интернационализации экономики на стадии ее глобальной интеграции. Для упрощения понимания целесообразно принципиально разделить все метакорпорации на два типа: национальные и международные, а международные, в свою очередь, подразделить на транснациональные (интернациональные), многонациональные (мультинациональные) и глобальные корпорации. Примечательно, что границы между многонациональным и глобальным типами достаточно условны и весьма подвижны, возможен переход одного типа в другой. Указанные типы отражают в действительности этапы корпоративного развития: переход от национальной к транснациональной компании, многонациональной и глобальной корпорации. Каждому этапу свойственен ряд признаков: взаимоотношения материнской компании и зарубежных филиалов; отношение к зарубежному рынку, уровень централизации принятия управленческих решений, контроль за деятельностью зарубежных филиалов; кадровая политика; организационная структура; информационные потоки.

Организационные структуры управления производственно-хозяйственной деятельностью метакорпораций в целом аналогичны структурам, используемым любыми крупными предприятиями (выделяются линейно-штабная, дивизиональная, матричная бизнес-структура), причем бизнес-структуры и отдельные юридические лица в составе метакорпорации не обязательно совпадают.

Современные изменения в организационных структурах метакорпораций связаны с внедрением комплексной стратегии, основанной на глобальном подходе, предусматривающем оптимизацию результата не для каждого отдельного звена, а для объединения в целом. Комплексная стратегия заключается в децентрализации управления международным концерном и создании региональных систем управления и организации производственной, финансовой деятельности зарубежных филиалов и дочерних фирм. Региональные системы управления подразделяются на три основных вида: главные региональные управления; региональные производственные управления (координирующие деятельность предприятий по производственной цепочке); функциональные региональные управления (обеспечивают специфические виды деятельности) (Голикова, 2006).

На сегодняшний день метакорпорации, действующие в различных отраслях обрабатывающей, добывающей, нефтехимической и нефтегазовой промышленности, электронике, разных отраслях машиностроения, координируют свое производство и сбыт предприятиями, разбросанными по всему миру, управляют процессами международной кооперации и специализации в глобальных масштабах. Располагая универсальной промышленной базой, метакорпорации проводят такую производственно-торговую политику, которая обеспечивает высокоэффективное планирование производства, товарного рынка, динамичную политику в области капиталовложений и научно-исследовательских работ в национальном, континентальном и международном масштабах для всех подразделений (филиалов) материнской компании как единого целого. Манипулируя политикой трансфертных цен крупные, объединенные корпоративные образования способны контролировать значительную часть рынка продаж, воздействовать на уровень цен и тем самым оказывать мощное давление на экономическую политику государств. Часто их деятельность влияет на размеры и распределение национального продукта, направленность капиталовложений, уровень занятости и покупательскую способность населения стран.

Тесная интеграция метакорпораций между собой порождает все более крупные объединения, между которыми также формируются взаимосвязи. В складывающихся обстоятельствах речь идет о формировании некоторой глобальной институциональной структуры - мировой системы метакорпораций (МСM). С точки зрения организации МСМ представляет сеть корпоративных образований. С правовой точки зрения МСМ представляет собой совокупность множества юридических лиц, связанных между собой определенными 
механизмами (системами перекрестного участия, договоров и личных уний). МСМ обладает множеством различных преимуществ, связанных прежде всего с гибкостью и мобильностью, но имеет и ряд недостатков. В общем, процесс формирования общих норм в МСМ затруднен тем, что в различных государствах система отношений между компаниями, между компаниями и правительством, между менеджментом и собственниками основана на различных принципах. Самостоятельную проблему образует правовое регулирование МСМ. Возникает необходимость в создании специфических правовых форм, которые позволили бы МСМ функционировать в мировом хозяйстве.

Тем не менее необходимо признать, что формирование МСМ - объективный процесс, обусловленный глобализацией, транснационализацией и международной экономической интеграцией, в целом оказывающий благоприятное влияние на международные отношения, прежде всего на состояние международной безопасности; способствуя развитию взаимозависимости различных государств, он делает любую агрессию стран, связанных системой транснациональных компаний, по отношению друг к другу невозможной или, по крайней мере, невыгодной (Голикова, 2006).

Какова же экономическая мощь системы метакорпораций в условиях современной мировой экономики? В рамках дальнейшего анализа целесообразно обратить внимание на некоторые экспертные оценки. Среди крупнейших метакорпораций сегодня есть своя элита суперкрупные фирмы (ТНК), соперничающие со многими государствами и по производству, и по бюджету, и по числу «подданных». Крупнейшие 100 метакорпораций по экспертным оценкам контролируют порядка $14 \%$ от совокупного размера зарубежных активов и более $15 \%$ от совокупного объема зарубежных продаж. По мнению западных исследователей, в настоящее время под их контролем находится более пятой части глобальных зарубежных активов. Динамика основных показателей деятельности крупнейших метакорпораций (ТНК) мира представлена в таблице 1.

Таблица 1

Статистический срез деятельности крупнейших ТНК мира с 2006 по 2008 год (UNCTAD. World Investment... 2009)

\begin{tabular}{|l|c|c|c|c|c|}
\hline \multicolumn{1}{|c|}{ Показатель } & $\mathbf{2 0 0 6}$ & $\mathbf{2 0 0 7}$ & $\begin{array}{c}\mathbf{2 0 0 6 - 2 0 0 7} \\
\text { (изменения } \\
\text { в \%) }\end{array}$ & $\mathbf{2 0 0 8}$ & $\begin{array}{c}\text { 2007-2008 } \\
\text { (изменения } \\
\text { в \%) }\end{array}$ \\
\hline $\begin{array}{l}\text { Активы (в млрд \$): } \\
\text { - за рубежом }\end{array}$ & 5245 & 6116 & 16,6 & 6094 & $-0,4$ \\
\hline - всего & 9239 & 10702 & 15,8 & 10687 & $-0,1$ \\
\hline $\begin{array}{l}\text { - доля зарубежных } \\
\text { активов (в \%) }\end{array}$ & 57 & 57 & 0,4 & 57 & $-0,1$ \\
\hline $\begin{array}{l}\text { Продажи (в млрд } \\
\text { \$): } \\
\text { - за рубежом }\end{array}$ & 4078 & 4936 & 21,0 & 5208 & 5,5 \\
\hline - всего & 7088 & 8078 & 14,0 & 8518 & 5,5 \\
\hline $\begin{array}{l}\text { - доля зарубежных } \\
\text { активов (в \%) }\end{array}$ & 58 & 61 & 3,6 & 61 & 0,0 \\
\hline $\begin{array}{l}\text { Занятость (в тыс.): } \\
\text { - за рубежом }\end{array}$ & 8582 & 8440 & $-1,66$ & 8898 & 5,4 \\
\hline - всего & 15388 & 14870 & $-3,4$ & 15302 & 2,9 \\
\hline $\begin{array}{l}\text { - доля зарубежных } \\
\text { активов (в \%) }\end{array}$ & 56 & 57 & 0,98 & 58 & 1,4 \\
\hline
\end{tabular}

Данные таблицы свидетельствуют о росте доли активов в абсолютном выражении (в млрд долларов США) с 2006 по 2007 год и некотором снижении этого показателя в 2008 году 
по сравнению с 2007-м, что может быть объективно продиктовано влиянием мирового финансового кризиса и снижением активности деятельности метакорпораций. С другой стороны, продажи стабильно растут как в относительных показателях, так и в процентном соотношении с 2006 по 2008 год.

Анализируя состав группы крупнейших транснациональных корпораций мира и изменения за последние десятилетия, можно проследить, как менялись доминирующие отрасли и регионы. Существует ряд рейтингов крупных компаний, которые (включая финансовые) по ряду показателей определяют состав группы успешнейших ТНК мира, что дает возможность отследить ее изменения за последние десятилетия. Сегодня многие западные рейтинговые агентства занимаются составлением и публикацией специальных корпоративных рейтингов (рейтингов корпоративного управления и контроля), которые должны стать важным компонентом оценки общего уровня инвестиционной привлекательности компаний и инструментом корпоративного управления относительно обеспечения эффективной реализации прав инвесторов. Наличие таких рейтингов и правил, признанных инвесторами из разных стран, - очень важное преимущество в условиях существующей острой конкуренции за привлечение капиталов.

По оценкам ежегодного рейтинга американского журнала Forbes, «Forbes Global 2000», по итогам 2009 года совокупный показатель объема продаж 100 крупнейших мировых корпораций составил 9663, 46 млрд долл., а размер активов - 41 415, 92 млрд долл. Необходимо отметить, что «Forbes» берет в качестве основы для рейтинга четыре основных показателя: рыночную капитализацию, объем активов, продаж и прибыли. Именно поэтому рейтинг журнала значительно отличается от многочисленных аналогов, которые строят сравнение компаний на каком-то одном показателе. В связи с чем список 10 крупнейших корпораций мира по оценке Forbes и по состоянию на сегодняшний день выглядит следующим образом (табл. 2).

Таблица 2

Список крупнейших корпораций мира («Forbes Global 2000» 2010)

(Forbes. Global 2000... 2011)

\begin{tabular}{|c|l|c|c|c|c|}
\hline $\begin{array}{c}\text { Ранг } \\
\text { место) }\end{array}$ & Компания & Страна & $\begin{array}{c}\text { Направление } \\
\text { деятельности }\end{array}$ & $\begin{array}{c}\text { Объем продаж } \\
\text { (млрд \$) }\end{array}$ & $\begin{array}{c}\text { Прибыль } \\
\text { (млрд \$) }\end{array}$ \\
\hline 1 & $\begin{array}{l}\text { JPMorgan } \\
\text { Chase }\end{array}$ & США & Банковский сектор & 115,63 & 11,65 \\
\hline 2 & $\begin{array}{l}\text { General } \\
\text { Electric }\end{array}$ & США & Конгломерат & 156,78 & 11,03 \\
\hline 3 & $\begin{array}{l}\text { Bank of } \\
\text { America }\end{array}$ & США & Банковский сектор & 150,45 & 6,28 \\
\hline 4 & ExxonMobil & США & $\begin{array}{c}\text { Нефтегазовые } \\
\text { операции }\end{array}$ & 275,56 & 19,28 \\
\hline 5 & ICBC & Китай & Банковский сектор & 71,86 & 16,27 \\
\hline 6 & $\begin{array}{l}\text { Banco } \\
\text { Santander }\end{array}$ & Испания & Банковский сектор & 109,57 & 12,34 \\
\hline 7 & Wells Fargo & США & Банковский сектор & 98,64 & 12,28 \\
\hline 8 & $\begin{array}{l}\text { HSBC } \\
\text { Holdings }\end{array}$ & $\begin{array}{c}\text { Великобрита } \\
\text { ния }\end{array}$ & Банковский сектор & 103,74 & 5,83 \\
\hline 9 & $\begin{array}{l}\text { Royal Dutch } \\
\text { Shell }\end{array}$ & Нидерланды & $\begin{array}{c}\text { Нефтегазовые } \\
\text { операции }\end{array}$ & 278,19 & 12,52 \\
\hline 10 & $\begin{array}{l}\text { JPMorgan } \\
\text { Chase }\end{array}$ & США & Банковский сектор & 115,63 & 11,65 \\
\hline
\end{tabular}

Как видно из таблицы 2, в 2010 году большее число крупнейших корпораций мира приходится на банковский сектор. При этом преобладающей страной базирования 
банковских ТНК является США.

Однако согласно другому рейтингу - «Fortune Global 500», - подготовленному журналом Fortune в 2010 году, десятка крупнейших корпораций по уровню дохода выглядела несколько иначе и представлена в основном компаниями нефтегазового сектора (табл. 3).

Таблица 3

Список крупнейших метакорпораций мира по уровню дохода

(«Fortune Global 500») (Fortune Global 500... 2011)

\begin{tabular}{|c|l|l|c|c|}
\hline $\begin{array}{c}\text { Ранг } \\
\text { место) }\end{array}$ & \multicolumn{1}{|c|}{ Компания } & Направление деятельности & $\begin{array}{c}\text { Доход } \\
\text { (млн \$) }\end{array}$ & $\begin{array}{c}\text { Прибыль } \\
\text { (млн \$) }\end{array}$ \\
\hline 1 & Wal-Mart Stores & Розничная торговля & 408,214 & 14,335 \\
\hline 2 & $\begin{array}{l}\text { Royal Dutch } \\
\text { Shell }\end{array}$ & Нефтегазовый сектор & 285,129 & 12,518 \\
\hline 3 & Exxon Mobil & Нефтегазовый сектор & 284,65 & 19,28 \\
\hline 4 & BP & Нефтегазовый сектор & 246,138 & 16,578 \\
\hline 5 & Toyota Motor & Автопромышленность & 204,106 & 2,256 \\
\hline 6 & $\begin{array}{l}\text { Japan Post } \\
\text { Нoldings }\end{array}$ & $\begin{array}{l}\text { Конгломерат (услуги связи - } \\
\text { почта, банковский сектор, } \\
\text { страхование, международный } \\
\text { бизнес) }\end{array}$ & 202,196 & \\
\hline 7 & Sinopec & Нефтегазовый сектор & 187,518 & 5,756 \\
\hline 8 & State Grid & $\begin{array}{l}\text { Энергетика (строительство } \\
\text { энергетических систем и } \\
\text { передача электроэнергии) }\end{array}$ & 184,496 & -343 \\
\hline 9 & AXA & Конгломерат (страхование) & 175,257 & 5,012 \\
\hline 10 & $\begin{array}{l}\text { China National } \\
\text { Petroleum }\end{array}$ & $\begin{array}{l}\text { Нефтегазовый сектор } \\
105,496\end{array}$ & 10,272 \\
\hline
\end{tabular}

Стоит отметить, что принципиальных и существенных изменений в 2010 году по сравнению с 2009-м не произошло, за некоторыми исключениями. Несмотря на влияние кризиса, интересен факт выхода на первое место крупнейшей американской корпорации в сфере розничной торговли - Wal-Mart Stores (в рейтинге «Fortune Global 500» в 2009 году эта компания занимала лишь третье место). Крупная автопромышленная японская ТНК Тoyota Motors также поднялась с 10-го на 5-е место (по сравнению с 2009 годом), а холдинг Japan Post Holdings. несмотря на встряску 2009 года и противодействие конкурентов, а также благодаря отказу правительства от планов приватизации компании (прежнее правительство с 2007 года планировало разделить компанию на четыре части и к 2017 году провести приватизацию) и активной финансовой поддержке, вышла с 11-го на 6-е место. Китайская THК State Grid поднялась с 15-го на 8-е место по сравнению с 2009 годом благодаря инновационному, промышленному и технологическому реформированию. Примечательно появление в списке на 9-м месте французского страхового конгломерата АХА, поскольку в 2009 году эта компания занимала лишь 73-е место. Такие изменения могут быть объяснены новой стратегией развития (захват новых рынков): активным использованием тактики слияния и поглощения других корпораций на рынке Великобритании и ростом доходов (на $50 \%$ по сравнению с 2009 годом) на рынках Азии, стремительно развивающихся и быстрорастущих государств Таиланда, Индонезии и Малайзии, где корпорация планирует увеличить этот показатель к 2013 году в 3 раза. Однако ряд компаний в 2010 годов не вошел в десятку лучших: американская Chevron - падение с 5-го на 11-е место, французская Total с 6-го на 14-е, нидерландская ING Group - с 8-го на 12-е.

Bce три перечисленные корпорации связывают снижение показателей своей хозяйственной деятельности с влиянием мирового финансового кризиса, но настроены оптимистично и планируют активизацию и повышение эффективности функционирования в 
ближайшем будущем, в частности в 2012-2013 годах (Fortune Global 500.. 2011]).

Не меньший интерес представляет анализ изменений списка крупнейших корпораций по странам. Стоит отметить, что согласно рейтингу «Forbes 2000», по итогам 2010 года относительно страны материнской компании из списка крупнейших наибольшее количество приходится на США (26 компаний). Россия занимает 6-е место и представлена лишь четырьмя компаниями: «Газпром», «Лукойл», «Роснефть», «Сбербанк» (табл. 4).

Таблица 4

Список крупнейших метакорпораций по странам («Forbes 2000»)

(Forbes. Global, 2000; Forbes. Global, 2010; Forbes. Global, 2011)

\begin{tabular}{|c|c|c|c|c|}
\hline $\begin{array}{c}\text { Место, } \\
\text { 2009-2010 } \\
\text { г. }\end{array}$ & $\begin{array}{c}\text { Количество } \\
\text { ТНК, } 2009 \text { г. (в } \\
\text { каждой стране) }\end{array}$ & $\begin{array}{c}\text { Количество } \\
\text { ТНК, } 2010 \text { г. (в } \\
\text { каждой стране) }\end{array}$ & $\begin{array}{c}\text { Страна } \\
\text { материнской } \\
\text { Компании, 2009 г. }\end{array}$ & $\begin{array}{c}\text { Страна } \\
\text { материнской } \\
\text { Компании, } 2010 \text { г. }\end{array}$ \\
\hline 10 & 1 & - & $\begin{array}{l}\text { Люксембург, } \\
\text { Канада, } \\
\text { Финляндия, } \\
\text { Гонконг, Норвегия, } \\
\text { Саудовская } \\
\text { Аравия, Южная } \\
\text { Корея }\end{array}$ & - \\
\hline 9 & 2 & 1 & Нидерланды & $\begin{array}{l}\text { Бельгия, Гонконг, } \\
\text { Норвегия, Южная } \\
\text { Корея, Швеция }\end{array}$ \\
\hline 8 & 3 & 2 & Бразилия, Россия & Нидерланды \\
\hline 7 & 4 & 3 & $\begin{array}{l}\text { Австралия, } \\
\text { Испания, Новая } \\
\text { Зеландия }\end{array}$ & Канада, Япония \\
\hline 6 & 6 & 4 & Китай, Италия & Россия, Испания \\
\hline 5 & 7 & 5 & Великобритания & $\begin{array}{l}\text { Австралия, } \\
\text { Бразилия, Италия, } \\
\text { Новая Зеландия }\end{array}$ \\
\hline 4 & 9 & 7 & Франция & Китай, Германия \\
\hline 3 & 10 & 8 & Германия & Франция \\
\hline 2 & 11 & 10 & Япония & Великобритания \\
\hline 1 & 24 & 26 & США & США \\
\hline
\end{tabular}

Таблица 4 показывает некоторые изменения списка крупнейших корпораций за последние два года; в частности, по итогам 2010 года в рейтинге заметно сокращение числа ТНК из Японии, отсутствие в списке корпораций Саудовской Аравии и Люксембурга, что, вероятно, частично продиктовано последствиями мирового финансового кризиса и неблагоприятной рыночной конъюнктурой в ряде отраслей. С другой стороны, одновременно наблюдается усиление позиций компаний США, Канады, Великобритании, России, Китая, Бразилии, Новой Зеландии. При этом примечательно, что наиболее прибыльные корпорации по уровню рентабельности сосредоточены в следующих отраслях (табл. 5). 
Список наиболее прибыльных метакорпораций мира по отраслям «Fortune Global 500», 2009 год (рентабельность в \% к 2008 году - отношение прибыли к затратам)

(Fortune Global 2000... 2011)

\begin{tabular}{|c|l|c|}
\hline $\begin{array}{c}\text { Ранг } \\
\text { (место в рейтинге) }\end{array}$ & \multicolumn{1}{|c|}{ Отрасль } & $\begin{array}{c}\text { Изменение в \% } \\
\text { к 2008 г. }\end{array}$ \\
\hline 1 & Горная промышленность, нефтедобыча & 19,8 \\
\hline 2 & Фармацевтика п & 19,1 \\
\hline 3 & Табачное производство & 12,3 \\
\hline 4 & Продукты питания и потребительские товары & 11,9 \\
\hline 5 & $\begin{array}{l}\text { Бытовые товары и продукты личного } \\
\text { потребления }\end{array}$ & 9,9 \\
\hline 6 & Телекоммуникации & 7,5 \\
\hline 7 & Машинная индустрия и строительные & 6,1 \\
\hline 8 & $\begin{array}{l}\text { Стеклопроизводство и } \\
\text { материалы }\end{array}$ \\
\hline 9 & Оборонная и авиапромышленность & 6,2 \\
\hline 10 & Судостроение & 6,1 \\
\hline
\end{tabular}

Относительно текущего состояния и перспектив развития деятельности крупнейших корпораций мира вызывает интерес оценка и прогноз, опубликованные в ежегодном отчете WIR10 [(UNCTAD. World Investment Report...2010]). Результаты указанного исследования свидетельствуют о серьезном негативном влиянии экономического и финансового кризиса как на мировую экономку в целом, так и на стратегические программы финансирования деятельности крупнейших метакорпораций мира, особенно в части движения прямых иностранных инвестиций за период 2008-2009 годов. Однако в 2010 году прослеживается некоторое улучшение степени оптимизма восприятия компаниями положения их бизнеса, окружающей среды и инвестиционного климата. В 2009 году 47\% респондентов проявляли пессимизм в отношении окружающей бизнес-среды и общеэкономической обстановки, в 2010-и зарегистрировано уменьшение респондентов с такими взглядами до 36\%. При этом стоит отметить значительно более оптимистичные настроения представителей корпораций на 2011 год и на более долгосрочную перспективу. Примечательно, что если в прогнозах на 2010 год лишь 13\% респондентов придерживались оптимистичных взглядов на изменение глобальной экономической обстановки, то в отношении 2011 года их доля достигла 47\%, а в прогнозе на 2012 год твердое большинство позитивных оценок составило 62\%. По мнению опрошенных, негативное влияние кризиса сохранится в 2011 году, а существенное улучшение экономической обстановки произойдет в 2012-м (UNCTAD. World Investment Prospects ... 2011).

Помимо этого, респонденты склонны выражать больший оптимизм относительно изменения инвестиционной среды их собственной корпорации, чем в отношении глобальной экономики. В частности, более $70 \%$ позитивно настроены на улучшение состояния их компаний в 2012 году, что приблизительно на 8\% превосходит долю позитивно настроенных на большие изменения глобальной экономики мира.

Однако другие участники рынка капиталов (прямых иностранных инвестиций) относятся к такой оптимистичной точке зрения настороженно. Например, большинство международных инвестиционных агентств склонны считать, что улучшение ситуации с движением прямых иностранных инвестиций произойдет не ранее 2013-2014 годов. Национальные инвестиционные компании, так же как и метакорпорации (ТНК), считают, что улучшение внутригосударственного инвестиционного климата произойдет ранее позитивных сдвигов в глобальной мировой экономике.

Несмотря на серьезные последствия глобального финансово-хозяйственного и экономического кризиса и на стратегические инвестиционные программы метакорпораций, 
значительного изъятия капиталовложений или продажи части зарубежных активов не произошло; напротив, в сложившейся ситуации корпорации продолжали и продолжают расширение зарубежной инвестиционной деятельности. Сейчас метакорпорации планируют сохранение и развитие своих инвестиционных программ. Порядка $43 \%$ респондентовпредставителей планируют усиление инвестиционной активности в 2011 году (что значительно больше уровня 2009-го) и около 58\% намерены значительно увеличить капиталовложения за рубеж в 2012 году. Согласно оценкам UNCTAD, объем прямых иностранных инвестиций по итогам 2011 года составит 1,3-1,5 трлн долл. США, а в 2012 году он достигнет 1,6-2 трлн долл. США (UNCTAD. World Investment Prospects... 2011).

Все вышесказанное позволяет говорить об очевидном: на современном этапе развития мировой экономики МСМ действительно способствует развитию производственных, научных и технологических связей между организациями в различных странах и регионах, a также играет определяющую роль в процессе международной конкуренции, сотрудничая и соперничая с малым и средним бизнесом.

МСМ содействует экономической интеграции, создавая устойчивые экономические связи между разными странами. Во многом благодаря этому происходит постепенное «растворение» национальных экономик в едином мировом хозяйстве, в результате чего чисто экономическими средствами, без применения насилия, спонтанно создается глобальная экономика.

Проведенный анализ позволяет говорить о том, что метакорпорации, функционирующие сегодня в самых различных секторах экономики и на всех уровнях экономической системы - от регионального до транснационального, характеризуются важнейшими тенденциями развития:

- транснационализация, т.е. стремление, осуществляя прямые иностранные инвестиции (ПИИ), расширять сферу своей деятельности в мировом масштабе, создавая сеть дочерних компаний, представительств и филиалов за рубежом;

- интеграция промышленных и кредитно-финансовых учреждений в рамках метакорпорации, т.е. участие банков и небанковских кредитно-финансовых учреждений в метакорпорациях.

\section{Список литературы}

1. Авдашева С. Теория организации отраслевых рынков / С. Авдашева, Н. Розанова. М.: Магистр, 1998.

2. Беляева И.Ю. Капитал финансово-промышленных корпоративных структур / И. Ю. Беляева, М. А. Эскандиров. - М.: Финансовая академия при Правительстве РФ, 1998.

3. Бутчиков С. Корпоративный сектор в переходной российской экономике / C. Бутчиков, Ю. Петров // Российский экономический журнал. 1997. № 8. С. 16

4. Винслав Ю. Становление холдинговых компаний: правовое и организационное обеспечение / Ю. Винслав, А. Лисов // Российский экономический журнал. 2000. № 56. С. 28.

5. Голикова Ю.А. Формирование современных корпоративных образований: учебное пособие. - Хабаровск: РИЦ ХГАЭП, 2006.

6. Забелин П.В. Основы корпоративного управления концернами. - М.: ПРИОР, 1998.

7. Лафта Дж.К. Эффективность менеджмента организации: учебное пособие. - М.: Русская Деловая Литература, 1999.

8. Московский общественный научный фонд. АНО «Проекты для будущего: научные и образовательные технологии». Интеграционные процессы, корпоративное управление и менеджмент в российских компаниях. URL: http://www.mpsf.org.

9. Уильямсон О.И. Экономические институты капитализма: фирмы, рынки, «отношенческая» контрактация. - СПб.: Лениздат, 1996.

10. Хвалей В.В. Курс правовых основ внешнеэкономической деятельности государств - 
участников СНГ (Россия, Беларусь, Украина) / В.В. Хвалей, Я.И. Функ. - Минск: Амалфея, 2000.

11. Шамхалов Ф. Государство и экономика. Основы взаимодействия. - М.: Экономика, 2000.

12. Annual reports on Russian economy. Trends and prospects. - Moscow: Institute for the Economy in Transition, 1992-1999.

13. Forbes. Global 2000. 2010. URL: http://www.forbes.com/lists/2009/18/global-200009 The-Global-2000 Rank.html.

14. Forbes. Global 2000. 2011. URL: http://www.forbes.com/lists/2010/18/global-200010_The-Global-2000_Rank.html.

15. Fortune Global 500. URL: Annual ranking of the world's largest corporations. 2010. http://money.cnn.com/magazines/fortune/global500/2009/performers/industries/profits/asset s.html.

16. Fortune Global 500. URL: Annual ranking of the world's largest corporations. 2011. http://money.cnn.com/magazines/fortune/global500/2010/full_list.

17. UNCTAD. World Investment Report $2009 . \quad$ URL: http://www.unctad.org/Templates/Search.asp?intItemID=2068\&lang=1\&frmSearchStr=corp oration \& frmCategory $=$ doc $\&$ section $=$ whole.

18. UNCTAD. World Investment Report 2010. URL: Overview. http://www.unctad.org/en/docs/wir2010overview_en.pdf.

19. UNCTAD. World Investment Prospects Survey 2010-2012. URL: http://www.unctad.org/en/docs/diaeia20104_en.pdf. 